\title{
Radioactive brain scanning in the management of cerebrovascular disease
}

\author{
JOHN MARSHALL AND MARY G. POPHAM \\ From the Institute of Neurology and National Hospital for Nervous Diseases, \\ Queen Square, London
}

Radioactive brain scanning has rapidly become established as a valuable tool in the diagnosis of cerebral neoplasms, augmenting the existing methods of investigation. Its place in the management of cerebrovascular lesions is less clear. Studies of brain scans in patients suspected of having a cerebral neoplasm showed that abnormal uptake of the isotope was sometimes seen in patients who proved to have a cerebrovascular lesion (Morrison, Afifi, Van Allen, and Evans, 1965; Quinn, Ciric, and Hauser, 1965; Schmukler and Workman, 1966; Witcofski, Maynard and Roper, 1966; Allen, Dick, Hightower, and Brown, 1967). Recently, more systematic studies of patients diagnosed as having a cerebrovascular lesion have been carried out, abnormal uptake being found with varying frequency according to the type of lesion and the time interval between the ictus and the scan (Glasgow, Currier, Goodrich, and Tutor, 1965; Overton, Haynie, and Snodgrass, 1965; Waxman, Ziegler, and Rubin, 1965; Ojemann, Aronow, and Sweet, 1966; Rhoton, Klinkerfuss, Lilly, and Ter-Pogossian, 1966; Zingesser, Mandell, and Schechter, 1966; Brown, Zingesser, and Scheinberg, 1967; Digiulio and Feringa, 1967; Glasgow, Currier, Goodrich, and Tutor, 1967; Molinari, Pircher, and Heyman, 1967; Gutterman and Shenkin, 1969; Usher and Quinn, 1969). The present study was undertaken in order to define more clearly the place of radioactive brain scanning in the management of patients with cerebrovascular disease.

\section{MATERIAL}

The series comprised 103 patients who on the basis of clinical assessment and examination of the cerebrospinal fluid were diagnosed as having suffered a cerebrovascular accident. There were 67 males with an average age of 56 years (range 23 to 74) and 36 females with an average age of 55 years (range 26 to 76). The series was divided according to the clinical type of the stroke, the vascular territory in which the lesion occurred, and the presumed pathology. Four clinical types were recognized: the completed stroke in which the neurological deficit came on within six hours and persisted to a substantial degree, the stroke-in-evolution in which the deficit took longer than six hours to reach its maximum and then persisted, the transient ischaemic attack (TIA) in which the signs and symptoms cleared within 24 hours and the reversible ischaemic neurological deficit (RIND) in which the deficit persisted longer than 24 hours but subsequently disappeared.

All the scans were made using $\mathrm{Hg}$-197 chlormerodrin $(10 \mu \mathrm{ci} / \mathrm{kg}$ body weight). Scanning was started one to six hours after injection, the usual time being three hours. Two views were taken routinely: the appropriate lateral and either an anteroposterior or posteroanterior view, depending on the findings on the lateral scan. The apparatus used was a Picker Magnoscanner with a 5 in. diameter crystal, although a few of the scans were made with an earlier model housing a 3 in. crystal. The collimator had a $7.5 \mathrm{~cm}$ focal distance and a resolution (FWHM) of $1.7 \mathrm{~cm}$.

The scans were reported by the two of us without reference to the clinical data.

\section{RESULTS}

The results of scanning in relation to the clinical type of the stroke are given in Table 1. This shows that 37 of the 82 patients $(45 \%)$ with a completed stroke had a positive scan, whereas in none of the 17 patients with either TIAs or RIND was the scan positive.

TABLE 1

RESULTS OF SCANNING IN RELATION TO CLINICAL TYPE OF STROKE

\begin{tabular}{lcrrr}
\hline \multicolumn{1}{c}{ Type of stroke } & Positive scan & Negative scan & Total \\
\hline Completed stroke & 37 & 45 & 82 \\
$\begin{array}{l}\text { Stroke-in-evolution } \\
\text { Transient ischaemic attack }\end{array}$ & 1 & 3 & 4 \\
$\begin{array}{l}\text { Reversible ischaemic } \\
\text { neurological defect }\end{array}$ & - & 6 & 11 \\
& 38 & 65 & 103 \\
\hline
\end{tabular}


The time after the stroke at which the scan was made had a marked influence upon the results. As the scans of the patients with TIAs and RIND were negative no matter at what stage they were done, these were excluded from the analysis. The remaining 86 patients with completed strokes or strokes-inevolution had 98 scans, the results in relation to the time of scanning being given in Table 2 and illustrated in Fig. 1. Positive scans clearly occur most frequently in the second and third week after the incident, the frequency rising to nearly $70 \%$.

The size of the region of abnormal uptake was also related to the time interval between the stroke and the scan. The size was estimated by measuring the longest diameter of the area of abnormal uptake in

\section{TA B LE 2}

PERCENTAGE OF POSITIVE SCANS RELATED TO TIME INTERVAL BETWEEN STROKE AND SCAN

\begin{tabular}{lccc}
\hline Interval & Positive & Negative & Per cent positive \\
\hline Less than 1 week & 3 & 6 & 33 \\
1 week- & 10 & 5 & 67 \\
2 weeks- & 9 & 6 & 60 \\
3 weeks- & 2 & 6 & 25 \\
4 weeks- & 3 & 7 & 30 \\
2 months- & 5 & 6 & 45 \\
4 months- & 3 & 7 & 30 \\
6 months- & 4 & 7 & 36 \\
1 year- & 1 & 5 & 20 \\
2 years- & 1 & 2 & 33 \\
\hline
\end{tabular}

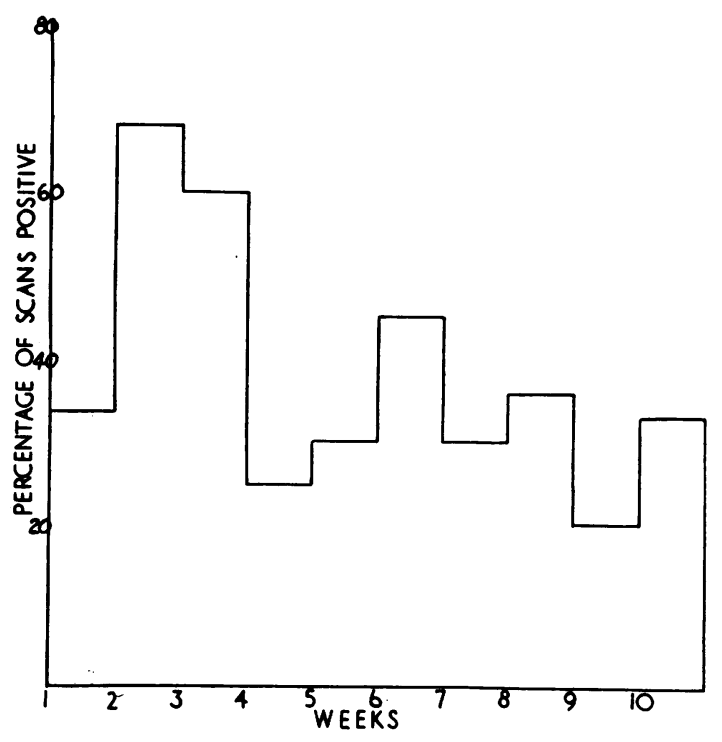

FIG. 1. Percentage of positive scans related to time interval between stroke and scan. the lateral scan and the diameter at right angles to $\bar{Z}$ this and the longest diameter in the anteroposterior or posteroanterior view. These three parametersō were multiplied to give an arbitrary measure of volume. Table 3 shows that the maximum size was reached in the second week after the stroke, afteros which there was a gradual decline.

Table 4 shows the effect of the site of the lesion upon the results of scanning. Six of the seven $\vec{F}$ patients $(86 \%)$ with lesions in the territory of the posterior cerebral artery as indicated by a hemianopias? as the sole clinical sign, had a positive scan, whereaso only 29 of the 87 patients (33\%) with lesions in the을 middle cerebral territory produced a positive result. $\frac{\bar{s}}{\bar{s}}$ Seven patients had signs and symptoms indicative of $a \nsubseteq$ lesion in the territory of the vertebrobasilar artery. Only one had a positive uptake, this being in the region of the occipital pole; this patient was the only. one of the seven whose signs included a hemianopia. $\vec{\omega}$

The pathology of a cerebrovascular lesion cannoto always be known with certainty during life. The diagnosis of cerebral haemorrhage in this series was? based upon the finding of frank non-traumatic blood ${ }_{\omega}^{\omega}$ in the cerebrospinal fluid at lumbar puncture. Theiv arteriovenous malformation and the two subdurifi haematomas were confirmed at angiography, thelatter being evacuated surgically. The category of 3 diffuse cerebral arteriosclerosis comprised those patients who presented with an acute focal episogeo in one vascular territory but in whom clinigial

TABLE 3

SIZE OF ABNORMAL UPTAKE RELATED TO TIME INTERVALO BETWEEN STROKE AND SCAN

\begin{tabular}{lcc}
\hline $\begin{array}{l}\text { Interval } \\
\text { (week) }\end{array}$ & $\begin{array}{c}\text { Positive scans } \\
\text { (no.) }\end{array}$ & $\begin{array}{c}\text { Mean size of uptake } \\
\text { (arbitrary u.) }\end{array}$ \\
\hline Less than 1 & 3 & 26 \\
$1-$ & 10 & 74 \\
$2-$ & 9 & 65 \\
3 to 7- & 5 & 67 \\
8 to 26- & 8 & 44 \\
More than 26- & 6 & 37 \\
\hline
\end{tabular}

TABLE 4

RESULTS OF SCANNING IN RELATION TO SITE OF LESION AS DIAGNOSED CLINICALLY

\begin{tabular}{|c|c|c|c|}
\hline Site & Positive & Negative & Tota \\
\hline $\begin{array}{ll}\text { Middle cerebral arterial } & \\
\text { territory: } & \text { left } \\
& \text { right }\end{array}$ & $\begin{array}{r}21 \\
8\end{array}$ & $\begin{array}{l}37 \\
21\end{array}$ & $\begin{array}{l}58 \\
29\end{array}$ \\
\hline $\begin{array}{l}\text { Posterior cerebral arterial } \\
\text { territory } \\
\text { Vertebrobasilar territory } \\
\text { Subdural haematoma }\end{array}$ & $\begin{array}{l}6 \\
1 \\
2\end{array}$ & $\begin{array}{l}1 \\
6 \\
0\end{array}$ & $\begin{array}{l}7 \\
7 \\
2\end{array}$ \\
\hline & 38 & 65 & \\
\hline
\end{tabular}


examination revealed evidence of widespread cerebrovascular disease. The results of scanning in these groups given in Table 5 reveal a high percentage of positives in cases of cerebral haemorrhage, with a lesser though substantial percentage in the case of infarcts.

When making scans it is important to note not only the time after the stroke at which the scan is performed, but also the time interval between the injection of the isotope and the scan. Table 6 shows that the area of the abnormal uptake achieves its maximum at three and a half hours, which is therefore the optimum time for scanning.

\section{DISCUSSION}

That the radioactive brain scan may be positive in a patient who has experienced a cerebrovascular accident is readily apparent from these results which merely confirm the findings of previous authors already quoted in the introduction. But to appreciate the exact role of scanning in the management of patients with cerebrovascular disease it is necessary to distinguish between the various clinical types of stroke and to take into account the time which has elapsed before the scan.

Amongst the patients who had experienced TIAs or RIND the scan was invariably negative. This finding is in keeping with expectation, for in TIAs

TABLE 5

RESULTS OF SCANNING IN RELATION TO PATHOLOGICAL DIAGNOSIS

\begin{tabular}{lcrr}
\hline & Positive & Negative & Total \\
\hline Infarction & 30 & 49 & 79 \\
Intracerebral haemorrhage & 6 & 1 & 7 \\
Subdural haematoma & 2 & 0 & 2 \\
Arteriovenous malformation & 0 & 1 & 1 \\
Diffuse cerebral & 0 & 3 & 3 \\
$\quad$ arteriosclerosis & 0 & 11 & 11 \\
Transient ischaemia & 38 & 65 & 103 \\
\hline
\end{tabular}

TABLE 6

INTERVAL BETWEEN INJECTION OF ISOTOPE AND SCAN RELATED TO SIZE OF ABNORMAL UPTAKE

\begin{tabular}{ccc}
\hline $\begin{array}{c}\text { Interval } \\
(\text { hr })\end{array}$ & $\begin{array}{c}\text { Positive scans } \\
(\text { no. })\end{array}$ & $\begin{array}{c}\text { Mean size of uptake } \\
\text { (arbitrary } u .)\end{array}$ \\
\hline 2 & 7 & 46 \\
$2 \frac{1}{2}$ & 8 & 44 \\
3 & 3 & 65 \\
$3 \frac{1}{2}$ & 3 & 78 \\
4 & 5 & 69 \\
$4 \frac{1}{2}$ & 4 & 64 \\
5 & 5 & 45 \\
\hline
\end{tabular}

it is assumed that there has been no significant degree of infarction, hence the blood-brain barrier should have remained intact. It accords with the findings of Rhoton et al. (1966) who found no positives among 50 patients with ischaemic cerebrovascular disease who at the time of scanning had no clinical deficit, but is slightly at variance with the experience of Ojemann et al. (1966), who found two positives among 15 scans in patients with TIAs in the carotid territory. It can certainly be said that a positive scan at any stage in a patient believed to be experiencing TIAs must give rise to doubts about the diagnosis. The practical importance is that cerebral tumours, particularly meningiomas, may present with TIAs. The finding of a positive scan in a patient ostensibly experiencing TIAs should therefore lead to further investigation as it is likely that he is suffering, not from cerebrovascular disease, but from a cerebral neoplasm.

In the case of patients who have experienced a completed stroke believed to be due to a cerebral infarction, the situation is somewhat different because the time interval between the stroke and the scan materially influences the interpretation of the results. In the present series only three out of nine patients had positive scans within the first week, which is in accord with the observation of Molinari et al. (1967) who found four out of 15 scans positive, Glasgow et al. (1965) with 12 out of 28 positive, and Gutterman and Shenkin (1969) with nine out of 21. All authors are agreed that the time at which the maximum number of positive scans will be found is in the second and third weeks after the stroke.

If the scan is made in the second or third week after the ictus, nearly $70 \%$ of scans will be positive. A single scan at this time is therefore of little diagnostic help, except perhaps that if it is negative the chances of the patient harbouring a tumour are small. But if a positive scan is obtained within the first few days after the stroke, serious consideration must be given to the possibility of a tumour being present. In these circumstances serial scans are extremely helpful as the amount of uptake should certainly be less at six weeks than it was in the initial scan. Scanning of patients with completed strokes due to infarction would therefore seem best carried out as soon as possible after the onset. When the scan is negative at this stage, the possibility of there being a tumour is remote and further scans need not be done. But if the scan is positive within the first few days, though this is perfectly compatible with infarction, it would be wise to scan again at six to eight weeks to make sure that the uptake has become less.

The fact that the scan is positive in a very high 
percentage of patients with intracerebral haemorrhage is of little practical significance as this type of cerebrovascular lesion is readily diagnosed in the great majority of cases by the presence of blood in the cerebrospinal fluid or by a shift of the midline structures in the echoencephalogram within the first 24 hours (Achar, Coe, and Marshall, 1966).

The results of scanning in relation to the vascular territory are as might be expected. The majority of lesions are in the territory of the middle cerebral artery and are readily picked up. The reason for the higher percentage of positives in lesions in the left as against the right middle cerebral arterial territory is not clear. Lesions in the territory of the posterior cerebral artery were also readily identified, which contrasts with the experience of Rhoton et al. (1966). As might be expected lesions in the vertebrobasilar territory are not detectable except when one of the posterior cerebral branches of the basilar artery is involved.

No attempt was made in this study systematically to compare the appearance of the area of abnormal uptake in the case of cerebrovascular disease with those in tumours. This has been done by Heiser and Quinn (1966) who compared 32 infarcts with 32 astrocytomas and found them to be indistinguishable by site, shape, intensity, homogeneity, or correlation with time, or by any combination of these factors. Our clinical experience accords with this view.

The place of scanning in the management of cerebrovascular disease is therefore to exclude the $5 \%$ or so of patients presenting as cerebrovascular accidents who in fact have tumours (Marquardsen, 1969). Scanning as soon as possible (within the first few days) after the ictus is the most helpful procedure as at this stage TIAs should certainly have a normal scan, as should the majority of completed strokes. A positive scan at this stage demands further action, full investigation in the case of TIAs and a second scan within the next few weeks in the case of completed strokes. By these measures a small but important group of apparent strokes will be recognized as the neoplasms they are and appropriate treatment undertaken.

\section{SUMMARY}

Radioactive brain scans were made in 103 patients who had a cerebrovascular accident. No positives were encountered among 11 patients with transient ischaemic attacks or in six with reversible ischaemic neurological defects. Forty-five per cent of the $\mathbf{8 2}$ patients with completed strokes had positive uptake, the figure rising to nearly $70 \%$ in those scanned in the second week. The place of scanning in the management of strokes is discussed in the light of these observations.

We wish to thank Dr. J. W. D. Bull in whose department the scans were made and the British Heart Foundation and the British Empire Cancer Campaign for financial support.

\section{REFERENCES}

Achar, V. S., Coe, R. P. K., and Marshall, J. (1966). Echoencepholography in the differential diagnosis of cerebral haemorrhage and infarction. Lancet, 1, 161-4.

Allen, M. B., Jr., Dick, D. A. L., Hightower, S. J., and Brown, M. (1967). The value and limitations of brain scanning: a review of 401 consecutive cases. Clin. Radiol., 18, 19-27.

Brown, A., Zingesser, L., and Scheinberg, L. C. (1967). Radioactive mercury-labelled chlormerodrin scans in cerebrovascular accidents. Neurology (Minneap.), 17, 405-412.

Digiulio, W., and Feringa, E. R. (1967). The mercury ${ }^{197}$ chlormerodrin brain scan in patients with cerebral infarction. $J$. nucl. Med., 8, 383.

Glasgow, J. L., Currier, R. D., Goodrich, J. K., and Tutor, F. T. (1965). Brain scans at varied intervals following C.V.A. J. nucl. Med., 6, 902-916.

-, Currier, R. D., Goodrich, J. K., and Tutor, F. T. (1967). Brain scans of cerebral infarcts with radioactive mercury.

Radiology, 88, 1086-1091. (1969). Cerebral scans in completed
Gutterman, P., and Shenkin, H. A. (196) strokes. Value in prognosis of clinical course. J. Amer. med N Ass., 207, 145-147.

Heiser, W. J., and Quinn, J. L. (1966). Analysis of brain scan patteris in cerebral ischaemia and astrocytoma. Arch. Neurol. (Chic.) 15, $125-128$.

Marquardsen, J. (1969). The Natural History of Acute Cerebrovascula Disease-A retrospective study of 769 patients. Munksgaar\& Copenhagen.

Molinari, G. F., Pircher, F., and Heyman, A. (1967). Serial brart scanning using technetium ${ }^{90 m}$ in patients with cerebral infares tion. Neurology (Minneap.), 17, 627-636.

Morrison, R. T., Afifi, A. K., Van Allen, M. W., and Evans, T. C. (1965). Scintiencephalography for the detection and localization of non-neoplastic intracranial lesions. J. nucl. Med., 6, 7-15.

Ojemann, R. G., Aronow, S., and Sweet, W. H. (1966). Scanning with positron-emitting isotopes in cerebrovascular disease. Acta Radiol. Diagn., 5, 894-905.

Overton, M. C., Haynie, T. P., and Snodgrass, S. R. (1965). Brain scans in nonneoplastic intracranial lesions. J. Amer. med. Ass., 191, $431-436$.

Quinn, J. L. Ciric, I., and Hauser, W. N. (1965). Analysis of 96 abnormal brain scans using Technetium ${ }^{90 m}$ (Pertechnetate form). J. Amer. med. Ass., 194, 157-160.

Rhoton, A. L., Klinkerfuss, G. H., Lilly, D. R., and Ter-Pogossian, M. M. (1966). Brain scanning in ischemic cerebrovascular disease. Arch. Neurol. (Chic.), 14, 506-511.

Schmukler, M., and Workman, J. B. (1966). The reliability of scintillation scanning for detection of intracranial lesions. $J$. nucl. Med., 7, 252-258.

Usher, M. S. and Quinn, J. L. (1969). Serial brain scanning with Technetium ${ }^{09 m}$ pertechnetate in cerebral infarction. Amer. J. Roentgenol., 105, 728-733.

Waxman, H. J., Ziegler, D. K., and Rubin, S. (1965). Brain scans in diagnosis of cerebrovascular disease. J. Amer. med. Ass., 192, 453-456.

Witcofski, R. L., Maynard, C. D., and Roper, T. J. (1966). A comparative analysis of the accuracy of the Technetium $00 \mathrm{~m}$ Pertechnetate brain scan: followup of 1000 patients. J. nucl. Med., 8, 187-196.

Zingesser, L., Mandell, S., and Schechter, M. (1966). Gamma en- N cephalograms in extracerebral haematomas. Acta Radiol. Diagn., 5, 972-980. 